\title{
Enhancing Learning Environments for Students Affected by Fetal Alcohol Spectrum Disorders: an Exploratory Study of Canadian Pre-service Teacher Knowledge and Conceptions
}

\author{
Jacqueline Pei ${ }^{1}$, Jenelle Job ${ }^{1}$, Cheryl Poth ${ }^{1}$, Anna O’Brien-Langer ${ }^{1,2}$, Wei Tang ${ }^{1}$ \\ ${ }^{1}$ Department of Educational Psychology, University of Alberta, Edmonton, Alberta, Canada \\ ${ }^{2}$ Independent Research Assistant, Edmonton, Alberta, Canada \\ Correspondence: Jacqueline Pei, Department of Educational Psychology, University of Alberta, Edmonton, Alberta, T6E
}

2G5, Canada

Received: June 15, 2015 Accepted: July 6, 2015 Online Published: July 20, 2015

doi:10.11114/jets.v3i5.955 URL: http://dx.doi.org/10.11114/jets.v3i5.955

\begin{abstract}
There is a pressing need for enhancing the learning environment for students affected by Fetal Alcohol Spectrum Disorders (FASDs). To develop relevant professional learning opportunities for teachers, a logical initial step is to explore the extent to which pre-service teachers accurately understand the unique neuropsychological functioning associated with FASDs and can apply their knowledge of how learning and development influence functions in the affected child. This research builds upon a theoretical framework operationalizing understanding as a composite of factual knowledge of the strengths and weaknesses of students with FASD and conceptions of how this underlying impairment impacts daily functions and the consequent potential for intervention by a classroom teacher (Job et al., 2013). The analysis of questionnaire data from 77 pre-service teachers revealed a limited knowledge of FASD and its associated deficits and a lack of ability for applying knowledge to classroom practice. The article concludes with a discussion of the implications for teacher education. In pre-service teacher education, knowledge about the causes and impairments associated with FASD can be taught, yet these are not useful in the absence conceptions that facilitate purposeful targeting of root issues for the individual in practice. Finally, we discuss the need for enhanced individualizing of programs for students with disabilities within an inclusive learning environment.
\end{abstract}

Keywords: teacher education, neuropsychological functioning, fetal alcohol spectrum disorders, developmental needs, classroom learning environment

\section{Introduction}

There is a pressing need for enhancing the learning environment for students affected by Fetal Alcohol Spectrum Disorders (FASDs). FASD is an umbrella term that refers to a range of physical, cognitive, emotional, and behavioral disabilities caused by prenatal alcohol exposure (PAE) (Alberta Learning, 2004; Stade et al., 2009). Affected individuals present with unique patterns of disability (Harpur, 2001) across many areas of functioning including but not limited to cognition, executive function, adaptive and social skills, memory, language, activity and attention, and mental health (Connor \& Streissguth 1996; Rasmussen, 2005; Pei, Denys, Hughes, \& Rasmussen, 2011). Given, that Health Canada (2006) estimates that more than 3000 Canadian babies are born with an FASD every year, it is essential that the school system is prepared for responding to the needs associated with PAE. Indeed, it is crucial that school-based personnel work with caregivers and allied professionals on strategies to support students with FASDs to achieve academic, social, emotional, and behavioral goals (Green, 2007). The trend toward an inclusive education model requires regular classroom teachers to be increasingly responsible for the education of students with FASDs.

Developing relevant professional development is necessary for enhancing the capacity of teachers to respond to the individual needs of students. In particular for children and adolescents affected by FASDs, the school environment can be particularly challenging because of their specific learning needs. The cognitive deficits associated with FASDs (e.g., weak memory retention, limitations in abstract reasoning, and poor information generalization) have significant effects on the affected student's learning and achievement (Duquette, Stodel, Fullarton \& Hagglund, 2006). Equally challenging are the behavioral effects of FASDs (e.g., mood swings, emotional outbursts, poor social reciprocity, and 
impulsivity), which have been shown to greatly impact a student's ability to form positive and appropriate relationships with peers or teachers (Kalberg \& Buckley, 2007; Roebuck, Mattson \& Riley, 1999). Due to issues with slow information processing and comprehension, students with FASD often misinterpret or miss social cues (Duquette et al., 2006; Green, 2007), and they may fail to learn skills necessary for appropriate conversation and interaction (Alberta Learning, 2004; Burgess \& Streissguth, 1992). Given these struggles, it not surprising that up to $60 \%$ of students with FASDs will experience some disruption to their education (e.g., suspension, expulsion, or drop out) before the age of 18 (Streissguth, 1997), consequently having a negative impact on their transition to productive adulthood. Classroom teachers might be well positioned to assist in a successful transition yet a lack of familiarity with affected students and limited education and training on FASDs leaves teachers without strategies to guide them in providing appropriate educational programming (Carpenter, 2011).

Researchers report successful educational experiences for students with FASDs are made possible by a number of factors; key among which are a welcoming school environment with strong administrative advocates for needed resources and teachers knowledgeable about how to respond to diverse student needs (Brownell \& Pajares, 1999; Cook, Tankersley, Cook, \& Landrum, 2000; Federico, Herrold \& Venn, 1999). Teacher knowledge about the nature and effects of FASDs, combined with positive beliefs and high teacher efficacy in working with students with special needs, are crucial factors in the successful education of these students (Cook et al., 2000). Although researchers disagree as to which teacher factors - knowledge, beliefs, or efficacy - are most influential in the education of students with disabilities, it is understood that once a teacher has entered a classroom, teacher efficacy and beliefs about certain student groups may be difficult to change (Bandura, 1997; Tait \& Purdie, 2000). For this reason is particularly prudent to examine pre-service teachers' conceptions of disabilities, or the generalized beliefs they bring into their teacher education program about working with special populations and how these perspectives influence the way they merge their knowledge base with practice to meet the learning needs of this population. There is an opportunity to explore conceptions, build knowledge, and inspire purposeful practice during the course of pre-service teacher training programs. Yet an essential beginning step is gaining an understanding of what knowledge and conceptions of students with disabilities pre-service teachers already possess.

Among the major elements of quality teaching, teacher beliefs are particularly significant factors in the education of students with disabilities (Sze, 2009; Shade \& Stewart, 2001). Teacher beliefs about the nature of disabilities and attitude toward students with these disabilities may impact a student's experience in the classroom. For example, when teachers attribute the causes of student learning or behavioral difficulties to home factors (e.g., dysfunctional family dynamics) they may be resistant to evaluating the role of their own instructional practices and other school factors in student difficulties (Mavropoulou \& Padeliadu, 2002; Soodak \& Podell, 1994). Alternatively, teachers may view student academic success as internally controlled by the student as they may be less willing to accept student failure or adapt their teaching methods to meet individual student needs (Brady \& Woolfson, 2008; Stein \& Wang, 1988). Thus if we want teachers to recognize and evolve the impact of their teaching we must first engage them in developing their knowledge and conceptions of the population - to foster optimal understanding and intervention practices.

Teachers who feel more competent and believe that their investment in student learning makes a difference have an easier time accepting some responsibility for student challenges (Brady \& Woolfson, 2008). Thus, opportunities for building competence through gaining accurate understandings of FASDs during their initial teacher education can influence practice and experiences throughout their careers. This information has important implications for teacher education, proposing that pre-service teacher preparation include not only training in relevant skills and strategies but address teacher beliefs about learners and the influence they have in student outcomes (Brady \& Woolfson, 2008).

A new reality faced by a growing number of practicing teachers is that the significant learning, social, and behavioral difficulties of students with FASDs are often beyond their current skills and notion of scope of practice (Carpenter, 2011; Job et al., 2012). Research among a group of European educators yields evidence of limited FASD awareness and knowledge (e.g., Blackburn, 2009; Blackburn, Carpenter, \& Egerton, 2010). In a study of 161 early childhood practitioners, $78 \%$ reported little to no knowledge about FASDs and maternal alcohol consumption (Blackburn, 2009) - a startling finding, given that $40 \%$ of their early education settings support children with FASDs. These findings underscore the genuine challenge faced by practitioners tasked with providing educational programming despite possessing inadequate knowledge. If teachers are to accommodate a variety of learning needs, it only follows that they would have the knowledge base to support their interventions (Ryan \& Ferguson 2006).

A small number of interventions have been reviewed to ameliorate the academic achievement, social skills and executive functioning of students with FASDs (Bertrand, 2009; Premji, Benzies, Serret, \& Hayden, 2007), with varying degrees of success. However, only one professional development program has been developed for teachers in need of FASD knowledge and evidence-based resources (Clark, 2012). In conjunction with the British Columbia Ministry of Education, Clark (2012) evaluated the effectiveness and fidelity of the Provincial Outreach Program for FASD 
(POPFASD) - a professional development program designed to assist elementary teachers in the inclusion of students with FASDs in the classroom. Teachers and students with and without FASDs were assigned to an intervention or comparison group and follow-up interviews were conducted with caregivers, principals, and teachers. Findings demonstrated positive change in teachers' perceptions and management of student behavior for participants in the intervention. Significant improvement in student behavior was also reported. These results lend support to the intervention as an effective professional development tool for elementary teachers working with affected students (Clark, 2012). Additional studies denote the association between teacher knowledge of FASDs and increased willingness to modify student expectations, adapt instruction, and change the classroom environment where possible to meet affected students' needs (Dybdahl and Ryan, 2009; Ryan \& Ferguson, 2006; Watson \& Westby, 2003).

Researchers and educators are beginning to respond to practicing teachers' need for improved education and training in the area of FASDs, yet examination of pre-service teachers' factual knowledge of the condition remains limited. Only one study to date has explored pre-service teachers' understanding of the causes of FASD and how this relates to their attributions of FASD-related problems and self-efficacy for teaching affected students (Atkinson, 2012). An interesting finding from this study was that although pre-service teachers correctly identified FASD-related problems as having complex causes, they reported feeling that such problems are less controllable by them. This is particularly troublesome because it suggests that pre-service teachers may have limited confidence that complex problems associated with FASDs can be remediated through the behavioral intervention strategies they are typically trained to use in the classroom (Atkinson, 2012). Clearly, further research is needed to evaluate pre-service teachers' knowledge of FASD and their perception of its link to student learning and behavior, using this information to inform supplemental education and training prior to practice. Given the importance of classroom teacher approaches with students with disabilities, it is crucial to explore the extent to which pre-service teachers are prepared with respect to accurate understanding of FASDs in order to address misconceptions and promote successful outcomes for affected and non-affected students alike.

\subsection{Theoretical Framework and Purpose}

This study builds upon a theoretical framework operationalizing understanding as a composite of factual knowledge of the strengths and weaknesses of students with FASD and conceptions of how this underlying impairment impacts daily functions and the consequent potential for intervention by a classroom teacher (Job et al., 2013). The investigation extends qualitative findings from recent research with school personnel, caregivers, and allied professionals, which revealed inconsistencies in stakeholder knowledge of FASDs and associated learning challenges, and a need for specialized education and teacher preparation (Job et al., 2012; Job et al. 2013). The objective of the present exploratory research study was to assess the extent to which pre-service teachers accurately understand the unique neuropsychological functioning associated with Fetal Alcohol Spectrum Disorders (FASDs) and how knowledge of learning and development influence functions in the affected child, with the aim of optimizing intervention efforts with this population.

\section{Methods}

The present study used a survey design to examine data patterns related to the knowledge and beliefs of pre-service teachers as they relate to teaching students with FASDs. Questionnaire items focused on evaluation of factual knowledge and conception of the disability as well as how pre-service teachers would approach learning needs and behavioral problems of affected students (Job et al., 2013). A web-based questionnaire was selected due to its efficiency in collecting a large amount of information within a short time frame and low cost of administration (de Vaus, 2001), using both Likert-style questions and open-ended questions. Multiple data sources afforded researchers greater confidence in the inferences generated.

\subsection{Respondents}

The study drew its convenience sample of 77 participants from the Faculty of Education's participant pool at a large, research-intensive university in western Canada. Following receipt of ethical approval by the university's Institutional Review Board, participants were sent the online questionnaire link by a research assistant in response to an email indicating their interest in participating. Students who chose to click the link were redirected to SurveyMonkey and informed that by choosing to begin the survey, they were consenting to their participation. A reminder email was sent after two weeks. At the end of the one-month administration period, the survey had a $100 \%$ response rate.

The majority of respondents identified themselves as female (86\%) with a mean age of 21.7 ; male participants identified a mean age of 22.9, for an overall age range of 18 to 41 years. There was an approximately equal distribution of respondents between elementary and secondary program training streams with 35 and 39 respondents respectively. For three respondents, no stream was specified. 


\subsection{Instrument}

This study reports the findings from 22 of 75 closed-ended items and three of six open-ended items on the questionnaire. The analysis of the remaining items is reported elsewhere. The first researcher-developed 10 items assessed respondents' knowledge and conceptions of FASD using a five-point Likert-type scale from 1 (strongly disagree) to 5 (strongly agree). For example, "Students with FASDs are unlikely to graduate from high school" (see Appendix A). The remaining items allowed for the examination of pre-service teachers' conceptions of controllability and stability of FASD. Respondents chose one of 10 data points between two opposing causes, demonstrating their level of agreement with one cause over another. For example, "The primary cause of problems associated with FASD is unchangeable or changeable." If a respondent selected data point 7 , then he/she would be expressing greater agreement with the latter statement but still have some reservation that the primary cause of FASD is completely unchangeable (see Appendix B). Items in this section were adapted from the Revised Causal Dimension Scale [CDSII] (McAuley, Duncan, \& Russell, 1992), which measures causal attributions across four scales: locus of causality, stability, personal control, and external control.

The open-ended questions further evaluated pre-service teachers' understanding of the disorder and associated developmental, learning, and behavioral challenges for affected students. The first question (Definition) asked respondents, "How would you define Fetal Alcohol Spectrum Disorder?" This provided information as to their awareness of and exposure to FASD and limited or advanced understanding of the condition. In the second question (Difficulties), "What sort of difficulties do you think a child affected by FASD might have in school?" respondents demonstrated their familiarity with the learning and behavioral challenges inherent in the disability. These two questions relate to the knowledge piece of the present study. The third question (Causes), "What do you believe is the primary cause of the problems associated with FASD?" assessed the conceptions pre-service teachers have about the bases of FASD-related difficulties.

\subsection{Data Analysis}

There were two data analysis steps that were undertaken concurrently related to the Quantitative and Qualitative data. The quantitative data was analyzed using the Predictive Analytics Software (PASW) Statistics version 20 to generate descriptive and inferential statistics. Mean comparisons were completed to evaluate whether differences among groups were related to program stream and knowledge of FASD as well as conceptions of affected students. Exploration of the relationships between individual items was conducted using crosstabs analyses. This allowed for developing an understanding of the influence of knowledge and perception on pre-service teachers' educational approach toward students with FASDs. Missing data was handled by pairwise deletion, which allows for the removal of specific missing values rather than removing cases in their entirety.

The analysis of qualitative data from the three open-ended questions was completed in three phases: (1) individual responses, (2) responses within elementary and secondary streams, and (3) responses across streams. Data coding was completed independently by two research assistants. During the first phase, an inductive process was used for generating codes for one respondent, and then used across respondents within the same stream. In the second phase, similarities and differences between codes for each stream were compared, and final codes were assigned by each research assistant. Once independent coding was completed for each question, the research assistants compared code lists. Inter-rater agreement on codes was achieved with $90 \%$ similarity. A final code list for each question within streams was developed through discussion until consensus was reached. In phase three, cross analysis highlighted code similarities and differences across streams. This allowed for further streamlining of the code lists and identification of categories and overarching themes across all respondents.

\section{Results}

The results are presented to address our study objective related to first to knowledge of FASD (e.g., understanding of cause, profile, and disability presentation) and second to conceptions and misconceptions of students with FASDs (e.g., caregiver effects, controllability of problem behaviors, and effectiveness of resources and interventions).

\subsection{Knowledge of FASD}

Overall thematic analysis of definitions led to differentiating between two categories of knowledge: basic knowledge and advanced. A basic knowledge was defined as having the ability to accurately identify FASD as a disorder caused by maternal consumption of alcohol during pregnancy yet unsuccessful in identifying any associated deficits or difficulties. In contrast, an advanced knowledge was defined as having the ability to accurately identify links among PAE and primary and secondary disabilities including learning challenges, problem behaviors, and social and emotional difficulties. A similar percentage of elementary and secondary stream respondents (SEC) were categorized has having an advanced knowledge ( $41.2 \%$ and $42.4 \%$ respectively), yet $55.9 \%$ of elementary-stream respondents (ELEM) were 
categorized as having a basic knowledge compared with only $47.5 \%$ of those from the secondary-stream. The remaining $2.9 \%$ of ELEM and $10.1 \%$ of SEC provided erroneous details or no response.

Identification of learning and behavioral difficulties revealed a breath of challenges that pre-service teachers perceive for affected students. When asked to delineate the difficulties a student with an FASD might encounter in school, respondents across streams correctly identified deficits from five major domains: behavioral, social, emotional, cognitive, and learning. These were combined into two deficit types: (1) observed difficulties (i.e., behavioral, social, and emotional deficits) and (2) underlying difficulties (i.e., cognitive and learning deficits). Responses across streams demonstrated interesting patterns; whereas observed difficulties of students with FASDs were identified more often than underlying difficulties, SEC accurately described a greater overall number of observed deficits than ELEM (52.5\% and $38.2 \%$ respectively). Behavioral deficits were reported with similar frequency across the streams as the most common observed difficulty. Almost half of the pre-service teacher participants were able to highlight two or more behavioral concerns (e.g., hyperactivity, impulsivity, and oppositional attitude) (ELEM: 47.1\%, SEC: 42.5\%) but they struggled to particularize the socio-emotional challenges encountered (ELEM: 20.6\%, SEC: 12.5\%) such as forming relationships, understanding social norms, and responding appropriately to social cues. Overall fewer, yet a similar number across streams of respondents (ELEM: 26.5\% and SEC: 25\%), accurately described underlying difficulties. For those that did, responses centered on weak memory retention, inattention, and poor comprehension, with a similar number identifying one or two areas of weakness $73.5 \%$ (ELEM and $77.5 \%$ of SEC).

\subsection{Conceptions and Misconceptions about Students with FASDs}

A great deal of variation was revealed in the responses about conceptions related to the causes of difficulties associated with FASDs. Qualitative analysis revealed differences between elementary- and secondary-stream pre-service teacher responses about FASD-related behaviors and challenges. ELEM attributed oppositional behaviors to school factors (e.g., lack of teacher support) and brain damage caused by PAE, whereas SEC linked difficulties to poor parenting, low intellect, and within-child factors (e.g., lack of self-regulation). These conceptual differences were also apparent on items evaluating pre-service teachers' understanding of the influence of FASD on student functioning, adapted from the CDSII (McAuley et al., 1992). In terms of locus of causality, elementary- and secondary-stream pre-service teachers demonstrated similar results, believing that FASD-related problems are situational (ELEM: $M=3.22$, SEC: $M=3.74$ ), reside somewhat inside the child (ELEM: $M=4.53$, SEC: $M=4.50$ ), and are moderately related to something about the child (ELEM: $M=4.72$, SEC: $M=4.53$ ). Greater divergence in conceptions of stability were revealed across streams: secondary-stream respondents reported a stronger belief in the permanence (SEC: $M=4.68$, ELEM: $M=3.75$ ) and fixedness (SEC: $M=5.71$ and $M=4.97$ ) of FASD causes as compared to their elementary-stream counterparts. With respect to controllability factors (i.e., personal or external control), elementary pre-service teachers provided ratings consistent with the belief that the problems experienced can be somewhat controlled by affected children but that there are aspects of the condition (e.g., extent of brain damage due to PAE) that may limit manageability. In contrast, secondary pre-service teachers were more likely to respond that students with FASDs do have power over their problems (SEC: $M=6.71$, ELEM: $M=6.19$ ) and should be able to regulate their behavior (SEC: $M=6.24$, ELEM: $M=5.64)$. Although secondary respondents demonstrated beliefs in personal control they also agreed that other people play a role in the control (SEC: $M=4.58$, ELEM: $M=3.61$ ) and management (SEC: $M=4.37$, ELEM: $M=3.67$ ) of FASD-related causes and difficulties.

Qualitative findings revealed that secondary-stream pre-service teachers attributed oppositional behaviors to poor parenting, low intellect, and within-child factors (e.g., self-regulation) whereas their elementary-stream counterparts focused on external factors (e.g., teacher support) and brain damage caused by PAE. Analysis of quantitative data reiterated these conceptions, demonstrating stream differences in pre-service teachers' views about the stability and controllability of the condition. With respect to the former, secondary-stream respondents noted a stronger belief in the permanence and fixedness of FASD causes compared to their elementary counterparts, which is consistent with emphasis on factors internal to the child that may be less amenable to external intervention. In addition, secondary-stream pre-service teachers demonstrated conviction in the regulatory power of affected students to monitor and manage their behavior. Conversely, elementary-stream pre-service teachers were less confident that students with FASDs could control difficulties as certain aspects of the condition (e.g., severity and extent of PAE-related brain damage) may limit manageability.

\subsection{Associations between Conceptions and Knowledge}

Findings from the crosstabs analysis revealed five significant relationships between individual knowledge and belief items. First, the statement that students with FASDs have low intelligence (Knowledge 2) was significantly linked to two different conceptions: individuals affected by FASD tend to be oppositional (Conception 1$)\left(X^{2}=15.35, d f=6, p<\right.$ $0.05)$ and many behavior problems in children affected by FASD are best attributed to poor parenting (Conception 2) 
$\left(X^{2}=39.24, d f=6, p<0.05\right)$. Second, the statement that the needs of affected students are best met through behavioral interventions (Conception 4) was significantly associated with three knowledge items: FASD is easily recognizable (Knowledge 1) $\left(X^{2}=33.86, d f=9, p<0.05\right)$, students with FASDs have low intelligence (Knowledge 2) $\left(X^{2}=15.66\right.$, $d f=6, p<0.05)$, and affected students are more susceptible to peer pressure (Knowledge 6) $\left(X^{2}=31.67, d f=9, p<\right.$ $0.05)$.

\section{Discussion}

Analyses revealed three areas for discussion related to the knowledge and conceptions of pre-service teachers about the functioning and capabilities of students with FASDs: (a) limited knowledge of FASD and its associated deficits may hinder teacher recognition of learning needs (b) lack of consensus regarding of conceptions of the causes of FASD and possible classroom interventions may limit teacher capacity to respond to learning needs, and (c) differences among streams in knowledge and conceptions may account for some of variations in teacher perspectives of stability and controllability of student learning and behavior.

The limited knowledge of FASD and its associated deficits may hinder teacher recognition of learning needs. Pre-service teachers are most aware of the behavioral features of FASD but are lacking in understanding about factors underlying observed behaviors, with secondary-stream respondents listing a greater number of behavioral and emotional deficits than their elementary-stream counterparts. The focus on observed difficulties has important implications not only for student success but also in mitigating areas of difficulty through planning and implementing needed interventions (Andreou \& Rapti, 2010) if pre-service teachers do not understand the association between outward actions and their underlying causes. Consequently, pre-service teachers may rely on training that equips them to respond to observed difficulties rather than exploring deeper for the root of those behaviors, leading to a justification for the use of familiar and trusted strategies rather than seeking information about teaching techniques and interventions specific to FASD. If they are unsuccessful in their treatment of observed behavioral challenges or if the interventions do not match the complex needs of students with FASDs, this can lead to a reduced positive impact of the intervention (Premji et al., 2007) as well as a diminished sense of self-confidence in the pre-service teacher's ability to control problem behaviors. Clearly, a delicate balance exists between what teachers understand about the underlying causes of observed behavioral problems in FASD and what they feel they can and cannot change in work with affected students. The challenge then is to provide teachers with specialized strategies that enable them to address observed and underlying difficulties of students with FASDs and manage this balance (Clark, 2012; Watson \& Westby, 2003).

Moreover, a lack of consensus regarding of conceptions of the causes of FASD and possible classroom interventions may limit teacher capacity to respond to learning needs. Knowledge informs conceptions about FASD; and therefore, it follows that training in the area of FASD shapes understanding and consequent intervention strategies. The knowledge statement that students with FASDs have low intelligence was significantly linked to two different conception statements (i.e., that individuals affected by FASD tend to be oppositional and that many of their behavioral issues are best attributed to poor parenting). The association between these statements is interesting. It may be that pre-service teachers connect lower intellectual functioning with home environments wherein children receive less attention and education from their parents. If this is the case, they may believe children might act out as a way to garner attention. An alternative explanation is that pre-service teachers are linking lower intelligence to brain damage as a result of PAE, which may create functional deficits such as oppositional behaviors. Or there may simply be the perception that PAE is associated with poor parenting, which also results in behavioral issues, and low intelligence is secondary to all of this. Each of these explanations may be a fit for some pre-service teachers, reflecting the diversity of possibility in the face of such a complex disorder. Consequently, it will be important for pre-service teachers to receive training that increases their knowledge of the complexity of the relationship between intelligence, behavior, and home environment, and equips them to include parents in the intervention process, focusing on modifying stressors across home and school and increasing protective factors (Olson, O'Connor, \& Fitzgerald, 2001) leading to more positive developmental and educational outcomes.

Differences among streams in knowledge and conceptions may require reframing teachers' developmental expectations. Expectant development trends seemed to be dominant in the conceptions held by pre-service teachers. Those planning to work with younger children perceived the child as more responsive to the classroom environment, and secondary teachers felt difficulties were more fixed and that the youth should be accountable for their behavior. This conception that youth with FASD may develop autonomy at the same rate as their typically developing peers in school has been posited as a contributing factor in the development of adverse outcomes for youth: the gap between them and their peers grows with age, yet support systems expect them to develop greater independence. Consequently, high rates of school dropout, mental health challenges, and justice involvement (i.e. problems with the law) begin to emerge in the secondary school years (Pei, 2011; Streissguth, 1997). 


\subsection{Implications \& Limitations}

This study has important implications for how preparing beginning teachers to undertake their classroom responsibilities is offered. In pre-service teacher education, knowledge about the causes and impairments associated with FASD can be taught, yet these are not useful in the absence of applied learning that facilitates purposeful targeting of root issues for the individual. First, pre-service teachers need access to experts to learn from and exposure to target populations. This is congruent with current opinion in the research literature in which it is noted that enhancement of specialized knowledge and skills are considered to be a pragmatic and effective approaches to improving teachers' work with students with disabilities and cultivating desired sensitivity and increased efficacy. Specifically, Cross and colleagues (2004) assert that given adequate training, teachers will be increasingly open to including students with severe and complex disabilities. Additionally, to increase functional knowledge, researchers recommend university courses and teacher in-services that focus on specific information about childhood disabilities including common learning challenges, intervention strategies, effective collaboration, monitoring of personal attitudes, and classroom management techniques for inclusive settings (Shade \& Stewart, 2001; Brownell \& Pajares, 1999; Campbell, Gilmore \& Cuskelly, 2003; Shippen, Crites, Houchins, Ramsey, \& Simon, 2005). Second, pre-service teachers need opportunities during their practicum experiences to engage in reflective activities that facilitate evolution of their conceptual understandings to support proactive approaches that foster student success. Researchers in the field support this notion, and it is noted that an integral component of pre-service teacher training appears to be practical work with students with special needs - an experience argued to be the most effective means of dispelling anxiety and increasing enthusiasm about teaching students with disabilities (Brady \& Woolfson, 2008; Romi \& Leyser, 2006; Jung, 2007).

Two limitations should be noted. First, as our sampling procedures drew from a participant pool of pre-service teachers at one institution, we acknowledge the limited generalizability of our findings. This is also true because the majority of study participants not only self-selected, but had not yet completed a formal teaching practicum, which may have influenced their views of the role of a classroom teacher and their willingness to complete the questionnaire. This leads to the other limitation: the use of a self-reported questionnaire where the data reflects only what the respondent was willing or able to articulate about a topic on which they may have limited knowledge and/or experience.

\section{Conclusion}

This study, exploring knowledge and conceptions of Canadian pre-service teachers about FASDs, contributes important understandings to the field of FASD teacher education. Specifically, we forward the need for strengthening connections between theory and practice during pre-service teacher education. This approach has the strong potential for enhancing teachers' capacity for making purposeful intervention decisions. Watson and Westby (2003) suggest that teachers' decisions about intervention are more dependent on their personal beliefs and knowledge of the affected student's difficulties than on formal training, especially when choosing behavioral intervention strategies (Watson \& Westby, 2003). Recognizing this link is critical to the development of teacher education programs that ensure comprehensive knowledge and training, and acknowledge that these elements inform teacher conceptions about affected students and affect their efficacy for planning and implementing interventions that lead to successful student outcomes.

\section{References}

Alberta Learning. (2004). Teaching students with fetal alcohol spectrum disorder: Building strengths, creating hope. Programming for Students with Special Needs. http://education.alberta.ca/media/377037/fasd.pdf

Andreou, E., \& Rapti, E. (2010). Teachers' causal attributions for behaviour problems and perceived efficacy for class management in relation to selected interventions. Behaviour Change, 27, 53-67. http://dx.doi.org/10.1375/bech.27.1.53

Atkinson, E. (2012). Pre-service teachers' causal attributions about FASD and their teaching self-efficacy. (Master's thesis). University of Alberta, AB. https://era.library.ualberta.ca/public/view/item/uuid:8d64f82b-af17-44f8-ba5e-f68f7130cbc1/DS1/Atkinson_Erin_ Fall\%202012.pdf

Bandura, A. (1997). Self-efficacy: The exercise of control. New York, NY: W.H. Freeman.

Bertrand, J. (2009). Interventions for children with fetal alcohol spectrum disorders (FASDs): Overview of findings for five innovative research projects. Research in Developmental Disabilities: A Multidisciplinary Journal, 30(5), 986-1006. http://dx.doi.org/10.1016/j.ridd.2009.02.003

Blackburn, C. (2009). FASD Building Bridges with Understanding: the acquisition of practitioner knowledge in relation to the management of support of children with Foetal Alcohol Syndrome and related disorders. http://www.sunfield.org.uk/pdf/FASD_Building_Bridges.pdf. 
Blackburn, C., Carpenter, B., \& Egerton, J. (2010). Shaping the future for children with foetal alcohol spectrum disorders. British Journal of Learning Support, $25(3), \quad 139-145$. http://dx.doi.org/10.1111/j.1467-9604.2010.01452.x

Brady, K., \& Woolfson, L. (2008). What teacher factors influence their attributions for children's difficulties in learning? British Journal of Educational Psychology, 78(4), 527-544. http://dx.doi.org/10.1348/000709907X268570

Brownell, M. T., \& Pajares, F. (1999). Teacher efficacy and perceived success in mainstreaming students with learning and behaviour problems. Teacher Education and Special Education, 22(3), 154-164. http://dx.doi.org/10.1177/088840649902200303

Burgess, D. M., \& Streissguth, A. P. (1992). Fetal alcohol syndrome and fetal alcohol effects: Principles for educators. The Phi Delta Kappan, 74(1), 24-30. http://www.jstor.org/stable/20404788

Campbell, J., Gilmore, L., \& Cuskelly, M. (2003). Changing student teachers' attitudes towards disability and inclusion. Journal of Intellectual \& Developmental Disability, 28(4), 369-379. http://dx.doi.org/10.1080/13668250310001616407

Carpenter, B. (2011). Pedagogically bereft: Improving learning outcomes for children with foetal alcohol spectrum disorders. British Journal of Special Education, 38(1), 37-43. http://dx.doi.org/10.1111/j.1467-8578.2011.00495.x

Clark, E. (2012). Assessment of a school-based intervention for elementary school students diagnosed with Fetal Alcohol Spectrum Disorder (FASD) (Doctoral dissertation). The University of British Columbia, Vancouver, BC. https://circle.ubc.ca/bitstream/handle/2429/42251/ubc_2012_fall_clark_erica.pdf?sequence=1\&sa=U\&ei=V4JPU8 PqEYWryATs54KABw\&ved=0CEIQFjAH\&usg=AFQjCNE_hyVaXtgETQCTKwdrmbFli_xgHQ

Connor, P. D., \& Streissguth, A. P. (1996) Effects of prenatal exposure to alcohol across the life span. Alcohol Health and Research World, 20, 170-174. http://pubs.niaaa.nih.gov/publications/ahrw20-3/170\%E2\%80\%93174.pdf

Cook, B. G., Tankersley, M., Cook, L., \& Landrum, T. J. (2000). Teachers' attitudes toward their included students with disabilities. Exceptional Children, 67(1), 115-135. http://dx.doi.org/10.1177/001440290006700108

Cross, A. F., Traub, E. K., Hutter-Pishgahi, L., \& Shelton, G. (2004). Elements of successful inclusion for children with significant disabilities. Topics in Early Childhood Special Education 24(3), 169-183. http://dx.doi.org/10.1177/02711214040240030401

de Vaus, D. (2001). Surveys in social research. New York: Routledge

Duquette, C., Stodel, E., Fullarton, S., \& Hagglund, K. (2006). Teaching students with developmental disabilities: Tips from teens and young adults with fetal alcohol spectrum disorder. Teaching Exceptional Children, 39(2), 28 -31.

Dybdahl, C. S., \& Ryan, S. (2009). Inclusion for students with fetal alcohol syndrome: Classroom teachers talk about practice. Preventing School Failure, 53(3), 185-195. http://dx.doi.org/10.3200/PSFL.53.3.185-196

Federico, M. A., Herrold, W., \& Venn, J. (1999). Helpful tips for successful inclusion. Teaching Exceptional Children $32(1), 76-82$.

Green, J. H. (2007). Fetal alcohol spectrum disorders: Understanding the effects of prenatal alcohol exposure and supporting students. Journal of School Health, $103-108$. http://dx.doi.org/10.1111/j.1746-1561.2007.00178.x

Harpur, L. (2001). FASD teens in the classroom: Basic strategies. Guidance \& Counseling, 17(1), $24-28$.

Health Canada. (2006). Fetal alcohol spectrum disorder: It's your health. http://www.hc-sc.gc.ca/hl-vs/iyh-vsv/diseases-maladies/fasd-etcaf-eng.php

Job, J. M., Poth, C. A., Pei, J., Caissie, B., Brandell, D., \& Macnab, J. (2013). Toward Better Collaboration in the Education of Students with Fetal Alcohol Spectrum Disorders: Integrating the Voices of Teachers, Administrators, Caregivers, and Allied Professionals. Qualitative Research in Education, 2(1), 38-64. http://dx.doi.org/10.4471/qre.2013.15

Job, J., Pasula-Carter, B., Brandell, D., Pei, J., Poth, C., \& Macnab, J. (2012). Toward better collaboration in the education of students with fetal alcohol spectrum disorders: Perspectives of teachers, administrators, caregivers, and allied professionals. Qualitative Research in Education, 2(1), 38-64. http://dx.doi.org/10.4471/qre.2013.15

Jung, W. S. (2007). Pre-service teacher training for successful inclusion. Education, 128(1), 106-113.

Kalberg, W. O., \& Buckley, D. (2007). FASD: What types of intervention and rehabilitation are useful? Neuroscience and Biobehavioural Reviews, 31(2), 278-285. http://dx.doi.org/10.1016/j.neubiorev.2006.06.014 
Mavropoulou, S., \& Padeliadu, S. (2002). Teachers' causal attributions for behaviour problems in relation to perceptions of control. Educational Psychology, 22(2), 191-202. http://dx.doi.org/10.1080/01443410120115256

McAuley, E., Duncan, T. E., \& Russell, D. W. (1992). Measuring causal attributions: The Revised Causal Dimension Scale (CDSII). Personality and Social Psychology Bulletin, 18, 566-573. http://dx.doi.org/10.1177/0146167292185006

Olson, H., O'Connor, M., \& Fitzgerald, H. (2001). Lessons learned from study of the developmental impact of parental alcohol use. Infant Mental Health Journal, 22, 271-290. http://dx.doi.org/10.1002/imhj.1001

Pei, J., Denys, K., Hughes, J., Rasmussen, C. (2011). Mental health issues in fetal alcohol spectrum disorder. Journal of Mental Health, 20(5), 473-483. http://dx.doi.org/10.3109/09638237.2011.577113..

Premji, S., Benzies, K., Serrett, K., \& Hayden, K. (2007). Research-based interventions for children and youth with fetal alcohol spectrum disorder: Revealing the gap. Child: Care, Health and Development, 33(4), 389-397. http://dx.doi.org/10.1111/j.1365-2214.2006.00692.x

Rasmussen, C. (2005). Executive functioning and working memory in Fetal Alcohol Spectrum Disorder. Alcoholism: Clinical and Experimental Research, 29, 1359-1367. http://dx.doi.org/10.1097/01.alc.0000175040.91007.d0

Roebuck, T. M., Mattson, S. N. and Riley, E. P. (1999). Behavioural and psychosocial profiles of alcohol-exposed children. Alcoholism: Clinical and Experimental Research, 23(6), 1070-1076. http://dx.doi.org/10.1111/j.1530-0277.1999.tb04227.x

Romi, S., \& Leyser, Y. (2006). Exploring inclusion and pre-service training needs: A study of variables associated with attitudes and self-efficacy beliefs. European Journal of Special Needs Education, 21(1), 85-105. http://dx.doi.org/10.1080/08856250500491880

Ryan, S., \& Ferguson, D. L. (2006). On, yet under, the radar: students with fetal alcohol syndrome disorder. Exceptional Children, 72(3), 363-379. http://dx.doi.org/10.1177/001440290607200307

Shade, R. A., \& Stewart, R. (2001). General education and special education pre-service teachers' attitudes toward inclusion. Preventing School Failure, 46(1), 37-41. http://dx.doi.org/10.1080/10459880109603342

Shippen, M. E., Crites, S. A., Houchins, D. E., Ramsey, M. L., \& Simon, M. (2005). Pre-service teachers perceptions of including students with disabilities. Teacher Education and Special Education, 28(2), 92-99. http://dx.doi.org/10.1177/088840640502800202

Soodak, L. C. \& Podell, D. M. (1994). Teachers' thinking about difficult-to-teach students. Journal of Educational Research, 88(1), 44-51. http://www.jstor.org/stable/27541953

Stade, B., Ali, A., Bennett, D., Campbell, D., Johnston, M., Lens, C., Tran, S., \& Koren, G. (2009). The burden of prenatal exposure to alcohol: Revised measurement of cost. Canadian Journal of Clinical Pharmacology and Therapeutics, 16(1), e91-e102.

Stein, M., \& Wang, M. C. (1988). Teacher development and school improvement: The process of teacher change. Teaching and Teacher Education, 4, 171-187. http://dx.doi.org/10.1016/0742-051X(88)90016-9

Streissguth, A. (1997). Fetal alcohol syndrome: A guide for families and communities. Baltimore, MD: Paul H. Brookes Publishing Co.

Sze, S. (2009). A literature review: Pre-service teachers' attitudes toward students with disabilities. Education, 130(1), 53-56.

Tait, K., \& Purdie, N. (2000). Attitudes toward disability: teacher education for inclusive environments in an Australian university. International Journal of Disability, Development, and Education, 47(1), 25-38. http://dx.doi.org/10.1080/103491200116110

Watson, S. M. R., \& Westby, C. E. (2003). Prenatal drug exposure: Implications for personnel preparation. Remedial and Special Education, 24(4), 204-214. http://dx.doi.org/10.1177/07419325030240040401 


\section{Appendix A}

Questionnaire Knowledge and conception statements

\begin{tabular}{|c|c|c|c|}
\hline Item & Knowledge & Item & Conception \\
\hline K1 & FASD is easily recognizable & $\mathrm{C} 1$ & $\begin{array}{l}\text { Individuals affected by FASD tend to be } \\
\text { oppositional }\end{array}$ \\
\hline $\mathrm{K} 2$ & $\begin{array}{l}\text { Students affected by FASD are unlikely to } \\
\text { graduate from high school }\end{array}$ & $\mathrm{C} 2$ & $\begin{array}{l}\text { Many behavior problems in children affected by } \\
\text { FASD are best attributed to poor parenting }\end{array}$ \\
\hline $\mathrm{K} 3$ & $\begin{array}{l}\text { Students affected by FASD are unlikely to } \\
\text { graduate from high school }\end{array}$ & $\mathrm{C} 3$ & $\begin{array}{l}\text { With the right intervention strategies, FASD } \\
\text { students can overcome their cognitive impairments }\end{array}$ \\
\hline K4 & $\begin{array}{l}\text { Most students with FASD receive funding for } \\
\text { their disabilities and therefore are placed in } \\
\text { special education classes or have additional } \\
\text { classroom support }\end{array}$ & $\mathrm{C} 4$ & $\begin{array}{l}\text { The needs of FASD students are best met through } \\
\text { behavioral interventions }\end{array}$ \\
\hline K5 & $\begin{array}{l}\text { Most students with FASD were diagnosed } \\
\text { before the age of six }\end{array}$ & & \\
\hline K6 & $\begin{array}{l}\text { Students with FASD are more susceptible to } \\
\text { peer pressure than other students }\end{array}$ & & \\
\hline KOpen 1 & $\begin{array}{l}\text { How would you define Fetal Alcohol Spectrum } \\
\text { Disorder? }\end{array}$ & COpen 1 & $\begin{array}{l}\text { What do you believe is the primary cause of the } \\
\text { problems associated with FASD? }\end{array}$ \\
\hline KOpen2 & $\begin{array}{l}\text { What sort of difficulties do you think a child } \\
\text { affected by FASD might have in school? }\end{array}$ & & \\
\hline
\end{tabular}

Notes. $\mathrm{K}=$ knowledge and $\mathrm{C}=$ conception followed by question number. Open identifies open-ended questions.

\section{Appendix B}

Items adapted from the Revised Causal Dimension Scale (CDSII)

For each of the questions below, indicate the number that best reflects your beliefs about the nature of the cause of problems associated with FASD.

The primary cause of problems associated with FASD

\begin{tabular}{|c|c|c|c|c|c|c|c|c|c|c|}
\hline $\begin{array}{l}\text { Reflects an aspect of the } \\
\text { child }\end{array}$ & 1 & 2 & 3 & 4 & 5 & 6 & 7 & 8 & 9 & $\begin{array}{l}\text { Reflects an aspect of the } \\
\text { situation }\end{array}$ \\
\hline $\begin{array}{l}\text { Is manageable by the } \\
\text { child }\end{array}$ & 1 & 2 & 3 & 4 & 5 & 6 & 7 & 8 & 9 & Is not manageable by the child \\
\hline Is permanent & 1 & 2 & 3 & 4 & 5 & 6 & 7 & 8 & 9 & Is not permanent \\
\hline Can be regulated by the child & 1 & 2 & 3 & 4 & 5 & 6 & 7 & 8 & 9 & Cannot be regulated by the child \\
\hline $\begin{array}{l}\text { Can be controlled by } \\
\text { others }\end{array}$ & 1 & 2 & 3 & 4 & 5 & 6 & 7 & 8 & 9 & $\begin{array}{l}\text { Cannot be controlled by } \\
\text { others }\end{array}$ \\
\hline Is inside of the child & 1 & 2 & 3 & 4 & 5 & 6 & 7 & 8 & 9 & Is not inside of the child \\
\hline Is stable over time & 1 & 2 & 3 & 4 & 5 & 6 & 7 & 8 & 9 & Is not stable over time \\
\hline $\begin{array}{l}\text { Is under the power of } \\
\text { other people }\end{array}$ & 1 & 2 & 3 & 4 & 5 & 6 & 7 & 8 & 9 & $\begin{array}{l}\text { Is not under the power of } \\
\text { other people }\end{array}$ \\
\hline $\begin{array}{l}\text { Is directly related to } \\
\text { something about the child }\end{array}$ & 1 & 2 & 3 & 4 & 5 & 6 & 7 & 8 & 9 & $\begin{array}{l}\text { Is not directly related to } \\
\text { something about the child }\end{array}$ \\
\hline $\begin{array}{l}\text { Is something the child has } \\
\text { power over }\end{array}$ & 1 & 2 & 3 & 4 & 5 & 6 & 7 & 8 & 9 & $\begin{array}{l}\text { Is not something the child has } \\
\text { power over }\end{array}$ \\
\hline Is unchangeable & 1 & 2 & 3 & 4 & 5 & 6 & 7 & 8 & 9 & Is changeable \\
\hline $\begin{array}{l}\text { Can be regulated by other } \\
\text { people }\end{array}$ & 1 & 2 & 3 & 4 & 5 & 6 & 7 & 8 & 9 & $\begin{array}{l}\text { Cannot be regulated by other } \\
\text { people }\end{array}$ \\
\hline
\end{tabular}

\section{$(\mathrm{cc})$ EY}

This work is licensed under a Creative Commons Attribution 3.0 License. 